\title{
Astrocyte Swelling And Vacuolation
}

National Cancer Institute

\section{Source}

National Cancer Institute. Astrocyte Swelling And Vacuolation. NCI Thesaurus. Code C161541.

A morphologic finding indicating the presence of astrocytes with intracytoplasmic swelling and vacuolation. 